\title{
Progressive resistance exercise in patients with pituitary adenoma: it does work
}

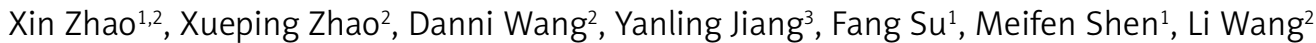

\author{
${ }^{1}$ Department of Neurosurgery, the First Affiliated Hospital of Soochow University, \\ Suzhou, Jiangsu Province, China \\ ${ }^{2}$ School of Nursing, Medical Department, Soochow University, Suzhou, Jiangsu \\ Province, China \\ ${ }^{3}$ Department of surgery, Dushu Lake Hospital Affiliated to Soochow University, \\ Suzhou, Jiangsu Province, China
}

Submitted: 28 June 2021; Accepted: 10 December 2021

Online publication: 14 December 2021

Arch Med Sci

DOI: https://doi.org/10.5114/aoms/144747

Copyright @ 2022 Termedia \& Banach

\section{Abstract}

Introduction: It is necessary to investigate the effects of progressive resistance exercise (PRE) in patients with pituitary adenomas after surgery, to provide insights into the clinical management of pituitary adenomas.

Material and methods: This study is a pre- and post-control experimental study design with the hypothesis that PRE can reduce postoperative fatigue. Patients with pituitary adenoma were included. The control group received conventional postoperative rehabilitation guidance, and the PRE group received PRE on the basis of routine rehabilitation. We measured the patient's muscle mass, muscle strength, vital capacity, and postoperative fatigue level 1 day before and 12 weeks after the operation. SPSS 22.0 was used for data analysis.

Results: A total of 89 patients were enrolled, including 44 in the control group and 45 in the PRE group. There was no significant difference in muscle mass between the 2 groups in the $12^{\text {th }}$ week after surgery, but the muscle loss of the left upper limb, trunk, and lower limbs of the control group was significantly higher than that of the PRE group (all $p<0.05$ ). The muscle strength and vital capacity of the control group were significantly lower than that of the intervention group, and the fatigue level was significantly higher than that of the PRE group (all $p<0.05$ ).

Conclusions: Progressive resistance exercise is helpful to combat muscle loss, muscle strength, and lung function decline caused by long-term bed rest in patients with pituitary adenoma after operation, thereby improving the postoperative fatigue level of patients.

Key words: pituitary adenomas, progressive resistance exercise, fatigue, care, management.

\section{Introduction}

Pituitary adenomas (PA) are the most common sellar tumours [1]. Epidemiologic studies [2, 3] show that pituitary adenomas are increasing in incidence (between 3.9 and 7.4 cases per 100,000 per year) and prevalence (76 to 116 cases per 100,000 population) in the general population (approximately 1 case per 1000 of the general population). Although most of them are benign, they can cause headaches, loss of vision, infertility, acromegaly, and other symptoms [4, 5]. Even after surgery, many

\author{
Corresponding authors: \\ Li Wang \\ Medical Department \\ School of Nursing \\ Soochow University \\ Suzhou, Jiangsu, China \\ Meifen Shen \\ Department \\ of Neurosurgery \\ the First Affiliated \\ Hospital of \\ Soochow University \\ Suzhou, Jiangsu, China \\ No. 1 Shizi Road \\ Suzhou, Jiangsu Province \\ China \\ Phone: 13815209071 \\ Fax: 001424863026 \\ E-mail:smf8165@126.com
}


patients suffer from long-term discomfort symptoms, among which fatigue is the most common [6]. Fatigue will appear in patients after surgery and will persist for several months [7]. In some patients, sleepiness and fatigue will last for several years or even longer, which seriously affects the quality of life of patients and is not conducive to their return to work and life $[8,9]$. Postoperative fatigue (POF) is a common complication after major surgical operations. It refers to the decline in physical strength and energy of the patient after the operation, and the inability to complete the usual physical and mental work, which can last several weeks to several months after the operation [10-12]. The mechanism of POF is not completely clear. At present, it is generally believed that the production of POF is related to increased catabolism caused by surgical stress, insufficient postoperative nutritional intake, and decreased postoperative activities [13, 14]. One or more of the above factors lead to a decrease in body health and skeletal muscles and decreased cardiopulmonary function, so the patient feels weak and exhausted, unable to complete the job at which he/she should be competent [15]. Therefore, the management of POF is vital to the life quality of patients.

Although the minimally invasive transsphenoidal approach for pituitary adenomas has been widely used, in order to prevent cerebrospinal fluid rhinorrhoea, patients still need to stay in bed for several days after surgery, even if they can get out of bed about 5-7 days after surgery, their daily routine activities are still restricted $[16,17]$. For example, it is forbidden to carry weight (over 20 pounds) or hold the breath forcefully, to avoid the increase of sphenoid sinus or intracranial pressure, causing cerebrospinal fluid rhinorrhoea and retrograde infection. Therefore, the patient's muscle loss, strength decrease, and reduced cardiopulmonary function are caused by prolonged bed rest and limited mobility after the operation of the pituitary adenoma, so that after the end of the rehabilitation period, the patient finds it particularly strenuous when engaging in normal preoperative activities again. This may be one of the factors leading to POF. Based on the above assumptions, we instructed patients to perform low-intensity progressive resistance exercises (PRE) from the postoperative bedridden period until the end of the rehabilitation period (12 weeks after surgery), to verify the relationship between postoperative activity reduction and PA patients' POF, and provide a basis for PA patients' POF intervention, thereby promoting postoperative recovery of $\mathrm{PA}$ patients and improving the quality of life of patients.

We hypothesized that progressive resistance exercise is beneficial to improve the muscle loss, muscle strength, lung function, and POF, thereby improving the quality of life in PA patients.

\section{Material and methods}

\section{Ethical considerations}

In this study, all methods were performed in accordance with the relevant guidelines and regulations. This present study was verified and approved by the Medical Ethics Committee of the First Affiliated Hospital of Soochow University (approval number: 2018179), and written informed consent was obtained from all the included patients. Our study was pre-registered in the China Clinical Trial Registry with Registration number: ChiCTR2100047172 (http://www.chictr.org.cn/showproj. aspx?proj=127529).

\section{Sample size calculation}

The sample size of this study was calculated by the comparison formula of 2 groups [18]: $n=(\lambda)$ $\left.\left(2\left(\arcsin \sqrt{P_{\max }}-\arcsin \sqrt{P_{\min }}\right)^{2}\right)\right)$, we presume that $\alpha=0.05, \beta=0.2$, and $v=3-1=2$, then $\lambda=8.84$, set $P \max , P \min$, respectively, as the maximum and minimum incidence of postoperative fatigue (90.06\% and $41.26 \%$ ), leading to a result of $n \approx 70$. Meanwhile, considering a loss rate of about $10 \%$ of the study population, i.e. the patients included in each group should be at least 40 with a ratio of $1: 1$, then at least 80 patients should be included.

\section{Patients}

We selected patients with pituitary adenoma, who were treated in the Department of Neurosurgery of the First Affiliated Hospital of Soochow University from January 2019 to September 2020, as the research population. The inclusion criteria of patients were as follows: 1) Preoperative disease was diagnosed as sellar area mass, sellar tumour, or pituitary adenoma, and the postoperative pathology report was of pituitary adenoma; 2) The patients underwent the neurosurgery by transnasal sinus approach; 3) The age of the patient was 18-65 years; 4) The patient gave informed consent and voluntarily participated in the study and accepted follow-up. The exclusion criteria for patients were as follows: 1) Those who had undergone surgery again within 12 weeks after surgery; 2) Those who had severe cardiopulmonary insufficiency and could not cooperate with exercise; 3) Those with disabled legs or knee joint and lumbar spine lesions, who could not tolerate muscle strength measurement; 4) Those who had metal grafts in their bodies that would affect the accuracy of body composition measurement; 5) Those who 
disagreed to participant or required withdrawal during the research process.

\section{Interventions}

We included patients from January 2019 to August 2019 in the control group according to the order of hospitalization, and the outpatient follow-up ended in November 2019; patients admitted from December 2019 to September 2020 were included in the PRE group and were followed up until December 2020.

The patients in the control group underwent routine care intervention, including admission 1 day before the operation, the patients completed preoperative examination and preparation, accepted nasal drops to clean the nasal cavity and shrink the mucosal blood vessels, trimmed the nose hair, and practiced using a cotton ball to plug the nose and breathe through the mouth. Patients fasted for $8 \mathrm{~h}$ before the operation and abstained from drinking for $4 \mathrm{~h}$. Patients accepted the postoperative ECG monitoring in bed, with oxygen inhalation until the vital signs were stable. Most patients included in this study were ventilated for 24-36 h after surgery to keep the body signs stable; we did not conduct PRE steps during the period of mechanical ventilation. We observed bleeding of the nasal gauze 1-2 days after the operation, and removed the non-operative and operative nasal cavity packing successively 3-6 days after the operation. Postoperative pain assessment was carried out, the patients were instructed to move their limbs on the bed, the lower limbs were massaged with a pressurized air pump, circulation was promoted, intake and output were recorded every day, and blood electrolyte was monitored.

In the PRE group, patients in the intervention group added postoperative resistance exercise guidance on the basis of the routine care intervention. The exercise plan was formed based on consulting relevant guidelines and expert consensus, and the final draft was revised after 2 rounds of expert letter inquiries. We mainly used low-intensity PRE supplemented by aerobic walking ex- ercises after getting out of bed. The muscles of the upper limbs, lower extremities, and trunk all underwent isotonic contraction exercises, which did not involve muscle isometric contraction exercises and would not cause the patient to hold their breath, and so were much safter. The PRE intervention was divided into 2 parts: the bed rest period and the resistance exercise after getting out of bed. The former used a 1-kg rice bag for resistance exercise, and the latter used a TheraBand elastic band for training. The colors of the elastic bands were brown, yellow, red, green, blue, indicating the intensity was from low to high, and the corresponding stretches were $1.1 \mathrm{~kg}, 1.4 \mathrm{~kg}$, and $1.4 \mathrm{~kg}$ when stretched to twice the original length (stretch rate $100 \%$ ). The specific PRE plans are presented in Tables I and II.

Both groups of patients received a pituitary adenoma surgery rehabilitation manual during preoperative education. The content of the manual of the control group mainly involved the postoperative diet, posture, and instructions. The rehabilitation manual of the PRE patients included added content about the PRE details. The rehabilitation exercise program and exercise diary were added for the patients to record after study and practice. We conducted telephone follow-ups at the $1^{\text {st }}, 2^{\text {nd }}$, $4^{\text {th }}$, and $7^{\text {th }}$ week after discharge from the hospital and the $11^{\text {th }}$ week after the operation. The follow-up of the patients in the control group mainly involved their recovery after discharge, including polydipsia, polyuria, and cerebrospinal fluid, and we reminded the patients about the medication for symptoms such as rhinorrhoea. In addition to the above follow-up content, patients in the PRE group were also asked about their exercise status, whether they could complete the exercise according to the plan, whether the exercise was difficult, and whether there was any abnormality during the exercise. Meanwhile, they were reminded to continue exercising and record it in the exercise diary. In the last follow-up call, the patient was reminded to follow up in time in the next week and complete the measurement of related indicators.

Table I. Exercise plan for postoperative bed-rest period

\begin{tabular}{|c|c|c|}
\hline Timepoint & Exercise & Frequency \\
\hline 1-2 days after surgery & \multirow{3}{*}{$\begin{array}{l}\text { 1) Half-recumbent short-lever Asuka (no } \\
\text { resistance) } \\
\text { 2) Plantar flexion, dorsiflexion of the foot } \\
\text { 3) Half-recumbent anti-flood (1 kg rice } \\
\text { bag) } \\
\text { 4) Quadriceps exercise } \\
\text { 5) Hip bridge movement }\end{array}$} & $\begin{array}{l}10 \text { times/group } 2 \text { groups, rest for } 2 \text { min } \\
\text { between groups, once in the morning } \\
\text { and once in the evening }\end{array}$ \\
\hline 3-4 days after surgery & & $\begin{array}{l}3,4) 5-10 \text { times/group }{ }^{\star} 2 \text { groups, } \\
\text { 5) } 5 \text { times/group } 2 \text { groups. Rest for } 2 \text { min } \\
\text { between each group, once in the morning } \\
\text { and once in the evening }\end{array}$ \\
\hline $\begin{array}{l}5 \text { days after surgery to get } \\
\text { out of bed }\end{array}$ & & $\begin{array}{l}3,4) 10-15 \text { times/group } 2 \text { groups, } \\
5 \text { ) } 5-10 \text { times/group } 2 \text { groups. Rest for } \\
2 \text { min between each group, once in the } \\
\text { morning and once in the evening }\end{array}$ \\
\hline
\end{tabular}


Table II. Exercise plan after getting out of bed

\begin{tabular}{|c|c|c|}
\hline Timepoint & Exercise & Frequency \\
\hline $\begin{array}{l}\text { After getting out of } \\
\text { bed to } 1 \text { month after } \\
\text { surgery }\end{array}$ & \multirow[t]{3}{*}{$\begin{array}{l}\text { 6) Chest and back muscles exercises. } \\
\text { 7) Lumbar and abdominal muscles } \\
\text { exercises. } \\
\text { 8) Upper arm muscles exercises. } \\
\text { 9) Lower limb muscles exercises (6-9- } \\
\text { are elastic band resistance exercises) } \\
\text { 10) Walking/strive walking }\end{array}$} & $\begin{array}{l}6,8 \text { ) and } 7,9 \text { ) exercise every other day, } \\
\text { starting with } 5 \text { times/group } 2 \text { groups, } \\
\text { gradually increasing to } 10-15 \text { times/ } \\
\text { group } 2 \text { groups, rest between each group } \\
\text { for } 2 \text { min, practice each exeicise } 3 \text { times/ } \\
\text { week. 10) } 40-60 \text { steps } / \mathrm{min}, 10 \mathrm{~min} / \text { day }\end{array}$ \\
\hline $\begin{array}{l}1-2 \text { months after } \\
\text { surgery }\end{array}$ & & $\begin{array}{l}6,8) \text { and } 7,9) \text { interval training, each item is } \\
\text { gradually increased to } 15-20 \text { times/ } \\
\text { group* } 2 \text { groups, each group rests for } 2 \mathrm{~min} \text {, } \\
\text { each item is practiced } 3 \text { times/week. } \\
60-90 \mathrm{steps} / \mathrm{min}, 20 \mathrm{~min} / \text { day }\end{array}$ \\
\hline $\begin{array}{l}2-3 \text { months after } \\
\text { surgery }\end{array}$ & & $\begin{array}{l}6,8) \text { and } 7,9 \text { ) interval practice, gradually } \\
\text { increase to } 20-25 \text { times/group* } 2 \text { groups, rest } \\
2 \text { min between each group, each excise } \\
3 \text { times/week. } 90-120 \text { steps/min, } 30 \text { min/day }\end{array}$ \\
\hline
\end{tabular}

\section{Outcome assessments}

The main outcome indicator of this study was the patient's fatigue level, and the secondary outcome indicators were muscle mass, muscle strength, and vital capacity. Among them, the level of fatigue was measured using the Multidimensional Fatigue Inventory (MFI-20), which was designed by Smets $E$ of the University of Amsterdam School of Medicine in the Netherlands in 1993. It contains 20 items and is divided into 5 dimensions. They are general fatigue, physical fatigue, mental fatigue, decreased vitality, and lack of motivation. Each dimension contains 4 items. The Likert 5-level scoring method was used to evaluate the degree of fatigue of the survey object within $24 \mathrm{~h}$. The higher the score, the greater the degree of fatigue. The Cronbach $\alpha$ coefficient of the Chinese version of the scale is 0.882 [19], which indicates good reliability and validity.

The muscle mass was detected by a body composition analyser (Inbody720Biospace Co., Japan), and the patient's body composition data was obtained through the bioimpedance measurement method, including the muscle mass of the upper limbs, lower limbs, and trunk.

Muscle strength included grip strength, leg strength, and back strength. A Xiangshan EH101 grip strength meter (Zhongshan, Guangdong, China) was used to measure the grip strength of the patient's hands. Both the leg strength and the waist strength were measured using a BCS-400 electronic back-force meter (Jiangsu Nantong Weighing Apparatus Factory, China). Leg strength was the extension strength of the knee muscles when standing and bending the knee at $115-125^{\circ}$. Back strength was the strength of the back when the upper body was tilted forward $30^{\circ}$ in a natural standing position. The above muscle strength was measured 3 times, and the average value was taken.
Vital capacity was measured by an electronic spirometer (manufactured by Nantong Yuejian Physical Testing Equipment Co., Ltd., FMJ-10000). After reaching the test state, we asked the patient to take a deep breath and exhale as quickly as possible against the mouthpiece, then we read the lung capacity at the end of the expiration, we took 3 measurements and recorded the average value.

\section{Statistical analysis}

We used SPSS 22.0 to build a database, and 2 people checked and entered all the data. The continuous data conforming to the normal distribution were described by the mean \pm standard deviation, and the independent sample $t$ test was used to compare the differences between groups. Continuous data that did not conform to the normal distribution were described by the median, and the Mann-Whitney $U$ test was used to compare the differences between groups. The count data were described by frequency and composition ratio, and the significance of the difference in frequency between groups was compared using the $\chi^{2}$ test. In this study, $p<0.05$ was taken as statistically significant.

\section{Results}

\section{The characteristics of included patients}

A total of 100 patients were identified initially; there were 5 patients who were unable to follow up for 12 weeks after the operation, and 6 patients were lost to follow-up due to being transferred to another area or hospital for treatment. Finally, a total of 89 patients were enrolled, including 44 in the control group and 45 in the PRE group. As presented in Table III, there were no significant differences in the gender, place of residence, marital status, childbirth, education level, occupational status, medical expenses payment method, tumour size, type of adenoma, mechani- 
cal ventilation, duration of surgery, and estimated blood loss during surgery between the control and PRE group (all $p>0.05$ ), indicating that the baseline data of the 2 groups of patients were relatively comparable.

\section{Body and muscle weight changes}

As presented in Table IV, there was no significant difference in body weight and muscle weight of upper limbs, lower limbs, and trunk between the 2 groups before surgery and at the $12^{\text {th }}$ week after surgery, but the postoperative muscle loss in the control group was significantly greater than that in the PRE group (all $p<0.05$ ).

\section{Muscle strength and vital capacity changes}

As shown in Table $V$, there was no significant difference in muscle strength and vital capacity between the 2 groups of PA patients before sur- gery (all $p>0.05$ ). At the $12^{\text {th }}$ week after surgery, the muscle strength and vital capacity of the intervention group were significantly higher than those of the control group (all $p<0.05$ ).

\section{Fatigue level}

As shown in Table VI, there was no significant difference between the groups of patients with pituitary adenoma in each dimension of fatigue before surgery (all $p>0.05$ ). At the $12^{\text {th }}$ week after surgery, the fatigue scores of each dimension of the control group were higher than those of the PRE group, and the difference was significant (all $p<0.05)$.

\section{Discussion}

It is well known that patients who stay in bed for a long time will experience muscle loss [20]. It is reported that healthy people who stay in bed

Table III. The general demographic data comparisons between control and PRE group

\begin{tabular}{|c|c|c|c|c|c|}
\hline \multicolumn{2}{|l|}{ Parameter } & \multirow{2}{*}{$\begin{array}{c}\text { Control group } \\
(n=44)\end{array}$} & \multirow{2}{*}{$\begin{array}{l}\text { PRE group } \\
(n=45) \\
23\end{array}$} & \multirow{2}{*}{$\begin{array}{c}\chi^{2} \\
3.41\end{array}$} & \multirow{2}{*}{$\begin{array}{c}P \text {-value } \\
0.07\end{array}$} \\
\hline Gender & Male & & & & \\
\hline & Female & 30 & 22 & & \\
\hline \multirow[t]{3}{*}{ Place of residence } & City & 32 & 35 & 4.91 & 0.09 \\
\hline & County & 9 & 3 & & \\
\hline & Rural area & 3 & 7 & & \\
\hline \multirow[t]{2}{*}{ Marital status } & Married & 41 & 42 & 1.00 & 0.65 \\
\hline & Unmarried & 3 & 3 & & \\
\hline \multirow[t]{2}{*}{ Childbirth } & Yes & 38 & 41 & 0.52 & 0.36 \\
\hline & No & 6 & 4 & & \\
\hline \multirow[t]{4}{*}{ Education level } & Primary school & 8 & 5 & 4.46 & 0.22 \\
\hline & Junior high school & 15 & 17 & & \\
\hline & Senior middle school & 15 & 10 & & \\
\hline & University & 6 & 13 & & \\
\hline \multirow[t]{2}{*}{ Occupational status } & Employed & 20 & 18 & 0.27 & 0.60 \\
\hline & Unemployed & 24 & 27 & & \\
\hline \multirow{2}{*}{$\begin{array}{l}\text { Medical expenses } \\
\text { payment method }\end{array}$} & Self-paid & 0 & 2 & 0.49 & 0.25 \\
\hline & Medical insurance & 44 & 43 & & \\
\hline \multirow[t]{3}{*}{ Tumour size } & Microadenoma & 4 & 4 & 0.24 & 0.89 \\
\hline & Large adenoma & 37 & 39 & & \\
\hline & Giant adenoma & 3 & 2 & & \\
\hline \multirow[t]{2}{*}{ Types of adenomas } & Nonfunctional & 30 & 29 & 0.14 & 0.71 \\
\hline & Functional & 14 & 16 & & \\
\hline \multirow{2}{*}{$\begin{array}{l}\text { Symptoms before } \\
\text { surgery }\end{array}$} & Yes & 38 & 42 & 0.32 & 0.23 \\
\hline & No & 6 & 3 & & \\
\hline \multirow{2}{*}{$\begin{array}{l}\text { Mechanical } \\
\text { ventilation }\end{array}$} & Yes & 40 & 41 & 1.66 & 0.19 \\
\hline & No & 4 & 4 & & \\
\hline \multicolumn{2}{|c|}{ Duration of surgery [min] } & $149.12 \pm 31.06$ & $151.88 \pm 28.06$ & 18.32 & 0.27 \\
\hline \multicolumn{2}{|c|}{ Estimated blood loss during surgery [ml] } & $308.85 \pm 50.23$ & $291.42 \pm 45.62$ & 22.71 & 0.13 \\
\hline
\end{tabular}


Table IV. Comparison of body and muscle weight and changes in patients with pituitary adenoma before and after surgery $(n=89)$

\begin{tabular}{|c|c|c|c|c|c|c|}
\hline Parameter & & Group & Median & Average rank & $z$ & $P$-value \\
\hline \multirow[t]{6}{*}{ Body weight } & \multirow[t]{2}{*}{ Before surgery } & Control group & 65.55 & 45.94 & -0.34 & 0.73 \\
\hline & & PRE group & 65.30 & 44.08 & & \\
\hline & \multirow[t]{2}{*}{ After surgery } & Control group & 65.60 & 44.00 & -0.36 & 0.72 \\
\hline & & PRE group & 68.20 & 45.98 & & \\
\hline & \multirow[t]{2}{*}{ Change } & Control group & 0.95 & 41.90 & -1.12 & 0.26 \\
\hline & & PRE group & 0.90 & 48.03 & & \\
\hline \multirow{6}{*}{$\begin{array}{l}\text { Skeletal } \\
\text { muscle } \\
\text { weight }\end{array}$} & \multirow[t]{2}{*}{ Before surgery } & Control group & 25.75 & 41.89 & -1.12 & 0.26 \\
\hline & & PRE group & 26.80 & 48.04 & & \\
\hline & \multirow[t]{2}{*}{ After surgery } & Control group & 23.40 & 39.98 & -1.81 & 0.07 \\
\hline & & PRE group & 27.00 & 49.91 & & \\
\hline & \multirow[t]{2}{*}{ Change } & Control group & -1.30 & 38.65 & -2.30 & 0.02 \\
\hline & & PRE group & -0.60 & 51.21 & & \\
\hline \multirow{6}{*}{$\begin{array}{l}\text { Left upper } \\
\text { limb muscle } \\
\text { weight }\end{array}$} & \multirow[t]{2}{*}{ Before surgery } & Control group & 2.50 & 43.68 & -0.48 & 0.63 \\
\hline & & PRE group & 2.48 & 46.29 & & \\
\hline & \multirow[t]{2}{*}{ After surgery } & Control group & 2.21 & 41.42 & -1.29 & 0.20 \\
\hline & & PRE group & 2.51 & 48.50 & & \\
\hline & \multirow[t]{2}{*}{ Change } & Control group & -0.16 & 39.33 & -2.05 & 0.04 \\
\hline & & PRE group & -0.05 & 50.54 & & \\
\hline \multirow{6}{*}{$\begin{array}{l}\text { Right upper } \\
\text { limb muscle } \\
\text { weight }\end{array}$} & \multirow[t]{2}{*}{ Before surgery } & Control group & 2.49 & 42.16 & -1.03 & 0.31 \\
\hline & & PRE group & 2.61 & 47.78 & & \\
\hline & \multirow[t]{2}{*}{ After surgery } & Control group & 2.23 & 40.57 & -1.60 & 0.11 \\
\hline & & PRE group & 2.52 & 49.33 & & \\
\hline & \multirow[t]{2}{*}{ Change } & Control group & -0.12 & 39.69 & -1.92 & 0.06 \\
\hline & & PRE group & -0.04 & 50.19 & & \\
\hline \multirow{6}{*}{$\begin{array}{l}\text { Trunk muscle } \\
\text { weight }\end{array}$} & \multirow[t]{2}{*}{ Before surgery } & Control group & 21.05 & 43.24 & -0.64 & 0.53 \\
\hline & & PRE group & 22.00 & 46.72 & & \\
\hline & \multirow[t]{2}{*}{ After surgery } & Control group & 19.45 & 41.08 & -1.42 & 0.16 \\
\hline & & PRE group & 21.60 & 48.83 & & \\
\hline & \multirow[t]{2}{*}{ Change } & Control group & -1.00 & 37.81 & -2.60 & 0.01 \\
\hline & & PRE group & -0.30 & 52.03 & & \\
\hline \multirow{6}{*}{$\begin{array}{l}\text { Muscle } \\
\text { weight } \\
\text { of lower } \\
\text { extremities }\end{array}$} & \multirow[t]{2}{*}{ Before surgery } & Control group & 13.65 & 41.61 & -1.12 & 0.22 \\
\hline & & PRE group & 15.34 & 48.31 & & \\
\hline & \multirow[t]{2}{*}{ After surgery } & Control group & 13.16 & 40.27 & -1.71 & 0.09 \\
\hline & & PRE group & 15.45 & 49.62 & & \\
\hline & \multirow[t]{2}{*}{ Change } & Control group & -0.40 & 37.91 & -2.56 & 0.01 \\
\hline & & PRE group & 0.08 & 51.93 & & \\
\hline
\end{tabular}

for 20 days will reduce the muscles of their lower limbs by $7-10 \%$ [21]. In this study, patients in the control group could get out of bed during the postoperative recovery period. However, based on the recommendations of "prevent colds, avoid hard coughs and sneezes; keep the stool unobstructed, avoid exerting breath to prevent cerebrospinal fluid leakage" in the discharge education, most of the patients were in the situation of "do not move without moving" and "do not dare to move casually" after being discharged from the hospital. So, the muscles also appear similar to "disuse atrophy" changes $[22,23]$. For safety reasons, the exercise program intensity of the intervention group was relatively low. According to reports [24, 25], medium- to high-intensity resistance exercises have muscle-building effects. Therefore, although patients in the PRE group cooperated with the exercise program, they did not see a significant increase in muscle mass, so that at the $12^{\text {th }}$ week after the operation there were only significant differences in the amount of changes in the left upper 
Table V. Comparison of muscle strength and vital capacity of patients with pituitary adenoma before and after surgery

\begin{tabular}{|c|c|c|c|c|c|c|}
\hline Parameter & & Group & Median & Average rank & $z$ & $P$-value \\
\hline \multirow{4}{*}{$\begin{array}{l}\text { Left upper } \\
\text { limb } \\
\text { strength }\end{array}$} & Before surgery & Control group & 27.55 & 41.94 & -1.10 & 0.27 \\
\hline & & PRE group & 29.20 & 47.99 & & \\
\hline & After surgery & Control group & 25.40 & 37.01 & -2.89 & 0.004 \\
\hline & & PRE group & 28.80 & 52.81 & & \\
\hline \multirow{4}{*}{$\begin{array}{l}\text { Right } \\
\text { upper limb } \\
\text { strength }\end{array}$} & Before surgery & Control group & 28.65 & 41.85 & -1.14 & 0.26 \\
\hline & & PRE group & 30.50 & 48.08 & & \\
\hline & After surgery & Control group & 26.45 & 36.76 & -2.98 & 0.003 \\
\hline & & PRE group & 32.70 & 53.06 & & \\
\hline \multirow{4}{*}{$\begin{array}{l}\text { Back } \\
\text { strength }\end{array}$} & Before surgery & Control group & 59.00 & 44.08 & -0.33 & 0.74 \\
\hline & & PRE group & 57.00 & 45.90 & & \\
\hline & After surgery & Control group & 46.00 & 35.10 & -3.58 & $<0.001$ \\
\hline & & PRE group & 69.00 & 54.68 & & \\
\hline \multirow{4}{*}{$\begin{array}{l}\text { Lower limb } \\
\text { strength }\end{array}$} & Before surgery & Control group & 71.50 & 41.94 & -1.10 & 0.27 \\
\hline & & PRE group & 82.00 & 47.99 & & \\
\hline & After surgery & Control group & 60.50 & 34.16 & -3.92 & $<0.001$ \\
\hline & & PRE group & 103.00 & 55.60 & & \\
\hline \multirow{4}{*}{$\begin{array}{l}\text { Vital } \\
\text { capacity }\end{array}$} & Before surgery & Control group & 2660.00 & 42.62 & -0.86 & 0.39 \\
\hline & & PRE group & 2660.00 & 47.32 & & \\
\hline & After surgery & Control group & 2412.50 & 38.42 & -2.38 & 0.02 \\
\hline & & PRE group & 2695.00 & 51.43 & & \\
\hline
\end{tabular}

Table VI. The fatigue level of patients with pituitary adenoma before and 3 months after surgery

\begin{tabular}{|c|c|c|c|c|c|c|}
\hline Parameter & & Group & Median & Average rank & $z$ & $P$-value \\
\hline \multirow{4}{*}{$\begin{array}{l}\text { Comprehen- } \\
\text { sive fatigue } \\
\text { level }\end{array}$} & Before surgery & Control group & 10.00 & 48.19 & -1.16 & 0.25 \\
\hline & & PRE group & 9.00 & 41.88 & & \\
\hline & After surgery & Control group & 11.00 & 58.00 & -4.72 & $<0.001$ \\
\hline & & PRE group & 7.00 & 32.29 & & \\
\hline \multirow{4}{*}{$\begin{array}{l}\text { Physical } \\
\text { fatigue level }\end{array}$} & Before surgery & Control group & 10.00 & 44.72 & -0.10 & 0.92 \\
\hline & & PRE group & 1100 & 45.28 & & \\
\hline & After surgery & Control group & 13.00 & 57.68 & -4.63 & $<0.001$ \\
\hline & & PRE group & 10.00 & 32.60 & & \\
\hline \multirow{4}{*}{$\begin{array}{l}\text { Reduced } \\
\text { activity }\end{array}$} & Before surgery & Control group & 9.50 & 41.68 & -1.21 & 0.23 \\
\hline & & PRE group & 11.00 & 48.24 & & \\
\hline & After surgery & Control group & 13.50 & 56.77 & -4.27 & $<0.001$ \\
\hline & & PRE group & 10.00 & 33.49 & & \\
\hline \multirow{4}{*}{$\begin{array}{l}\text { Reduced } \\
\text { motivation }\end{array}$} & Before surgery & Control group & 7.00 & 45.51 & -0.19 & 0.85 \\
\hline & & PRE group & 7.00 & 44.50 & & \\
\hline & After surgery & Control group & 8.00 & 56.44 & -4.17 & $<0.001$ \\
\hline & & PRE group & 6.00 & 33.81 & & \\
\hline \multirow{4}{*}{$\begin{array}{l}\text { Mental } \\
\text { fatigue level }\end{array}$} & Before surgery & Control group & 7.00 & 44.76 & -0.09 & 0.93 \\
\hline & & PRE group & 7.00 & 45.23 & & \\
\hline & After surgery & Control group & 8.00 & 50.52 & -2.01 & 0.04 \\
\hline & & PRE group & 6.00 & 39.60 & & \\
\hline
\end{tabular}


limb, trunk, and lower limb muscles between the 2 groups of patients, and there was no significant difference in muscle weight between the groups. However, it can be seen from the difference in the amount of muscle change that even low-intensity resistance exercises have the effect of resisting postoperative muscle loss. There is no significant difference in the muscle changes of the right upper limbs of the 2 groups of patients, which may be related to the dominant hand on the right side of most people. Although the control group did not perform resistance exercises, the right hand would get more than the left hand in daily life behaviours, thus alleviating the consumption of the right upper limb muscles.

The state of being in bed with less movement after surgery can cause a decline in muscle function [26, 27]. Previous studies [7, 28, 29] analysed healthy volunteers who had been in bed for 7 days and found that their muscle function changes were very similar to those seen in postoperative patients. The exercise program of this study was designed to take into account the exercise of upper limbs, lower limbs, and lower back muscles. Strike walking, as a kind of aerobic exercise, has also been proven to effectively enhance cardiopulmonary function [30-32]. Intervention is required at the $12^{\text {th }}$ week after surgery in this study; the hand grip strength, low back strength, lower limb strength, and lung capacity of the patients in the group were significantly greater than those in the control group, indicating that the exercise program in this study can effectively delay the decline of muscle strength and lung function in patients with PA, while the body strength and lung function are also an important part of physical fitness affects the patient's exercise ability. It is speculated that the progressive exercise program of this study can alleviate the decline in motor function during the rehabilitation of patients after PA by combating the decline in overall muscle strength and pulmonary function.

It has been reported that postoperative traumatic stress, reduced nutrient intake, and longterm bed rest are important causes of POF [13, $33,34]$. For PA patients, the surgical method of transsphenoidal approach is far less traumatic than craniotomy. Therefore, the trauma-stress response is limited, the operation does not involve the digestive system, and the patient can eat as needed after waking up under general anaesthesia [35]. The effect of nutritional limitation in POF is far less than that of major abdominal surgery. In order to avoid leakage of cerebrospinal fluid caused by increased intracranial pressure after surgery, patients usually need to stay in bed for 5-7 days, and their activities are still restricted after discharge [36, 37]. Decreased activity will cause the lack of stress stimulation of skeletal muscles, resulting in decreased muscle volume, and reduced muscle strength and cardiopulmonary function, and patients feel extra exertion during normal activities, resulting in POF [38, 39]. Therefore, POF in PA patients may be related to the bed rest after surgery and the reduction of activities [40-42]. The results of this study also confirmed this hypothesis. There was no significant difference in the fatigue scores of the 2 groups of patients before the operation. At the $12^{\text {th }}$ week after the operation, the fatigue scores of the intervention group were significantly lower than those of the control group. It may be explained by the fact that the progressive exercise partially offsets the postoperative muscle loss and the decline in motor function, so the patients in the PRE group use relatively little effort when performing some activities of daily living than the control group.

Several limitations in this present study must be considered: Firstly, we chose 1 day before and 12 weeks after operation to measure the associated parameters, researchers usually observed more than 3 months to assess the muscle loss and fatigue especially for a rehabilitation study, and the long-term effects and safety of a PRE program for PA needs further investigation. Secondly, we did not evaluate the life quality of patients - the indicators to evaluate the life quality of patients should be also indispensable to compare the effect of different interventions; further evaluations on the life quality of patients are needed in the future studies. Thirdly, limited by human and funding resources, it is difficult for us to maintain the blinding on allocation, intervention, and outcome assessment, which can lead to certain biases. Also, the sample size is small in this present study, so it is impossible to do stratified analysis based on factors such as age, tumour size etc. Therefore, more studies with rigorous design and larger sample size in different areas are needed to elucidate the role of PRE in the future.

In conclusion, the results of this study show that the PRE program for PA patients after surgery can partially offset the reduction of muscles, muscle strength, and lung function caused by bed rest and lack of movement, thereby effectively alleviating the level of POF. We hope that this result can be verified in more PA patients undergoing surgery, to provide new ideas for reducing POF and gaining reliable evidence for the postoperative rehabilitation guidelines of PA treatment and nursing care.

\section{Acknowledgments}

Xin Zhao and Xueping Zhao are equal contributor. 


\section{Conflict of interest}

The authors declare no conflict of interest.

\section{References}

1. Zhang J, Wang Y, Xu X, Gu Y, Huang F, Zhang M. Postoperative complications and quality of life in patients with pituitary adenoma. Gland Surg 2020; 9: 1521-9.

2. Daly AF, Beckers A. The epidemiology of pituitary adenomas. Endocrinol Metab Clin North Am 2020; 49: 347-55.

3. Iglesias P, Rodriguez Berrocal V, Diez JJ. Giant pituitary adenoma: histological types, clinical features and therapeutic approaches. Endocrine 2018; 61: 407-21.

4. Wenting W, Chao W, Meifen S. A qualitative study on the life experience of patients after pituitary adenoma. J Nurses Training 2017; 32: 1511-5.

5. Bryl M, Wozniak J, Dudek K, Czapiga B, Tabakow P. The quality of life after transnasal microsurgical and endoscopic resection of nonfunctioning pituitary adenoma. Adv Clin Exp Med 2020; 29: 921-8.

6. Vega-Beyhart A, Enriquez-Estrada VM, Bello-Chavolla OY, et al. Quality of life is significantly impaired in both secretory and non-functioning pituitary adenomas. Clin Endocrinol 2019; 90: 457-67.

7. Zargar-Shoshtari K, Hill AG. Postoperative fatigue: a review. World J Surg 2009; 33: 738-45.

8. Crouzeix G, Morello R, Thariat J, Morera J, Joubert M, Reznik Y. Quality of life but not cognition is impacted by radiotherapy in patients with non-functioning pituitary adenoma. Horm Metab Res 2019; 51: 178-85.

9. Wild CM, Stieg M, Stalla GK, Auer MK, Athanasoulia-Kaspar AP. Health-related quality of life in patients with non-functioning pituitary adenoma: a special focus on hydrocortisone replacement dose. Qual Life Res 2020; 29: 3325-31.

10. Dolci RLL, de Moraes LT, de Carvalho ACM, et al. Quality-of-life evaluation for patients submitted to nasal endoscopic surgery for resection of pituitary tumours. Eur Arch Otorhinolaryngol 2021; 278: 1411-8.

11. Rubin GJ, Hotopf M. Systematic review and meta-analysis of interventions for postoperative fatigue. Br J Surg 2002; 89: 971-84.

12. Rubin GJ, Hardy R, Hotopf $M$. A systematic review and meta-analysis of the incidence and severity of postoperative fatigue. J Psychosom Res 2004; 57: 317-26.

13. Jang MK, Oh EG, Lee H, Kim EH, Kim S. Postoperative symptoms and quality of life in pituitary macroadenomas patients. J Neurosci Nurs 2020; 52: 30-6.

14. Nostdahl T, Bernklev T, Fredheim OM, Paddison JS, Raeder J. Defining the cut-off point of clinically significant postoperative fatigue in three common fatigue scales. Qual Life Res 2019; 28: 991-1003.

15. Andela CD, Scharloo M, Pereira AM, Kaptein AA, Biermasz NR. Quality of life (QoL) impairments in patients with a pituitary adenoma: a systematic review of QoL studies. Pituitary 2015; 18: 752-76.

16. Wang $\mathrm{CH}$, Zhu N. Patient-reported quality of life after endoscopic surgery for pituitary lesions: a meta-analysis. J Biol Regul Homeost Agents 2018; 32: 1151-6.

17. Wei LF, Cai L, Wu ZB. Quality of life of patients with nonfunctioning pituitary adenoma: a meta-analysis. Zhonghua Yi Xue Za Zhi 2016; 96: 1481-4.

18. Jianwen Y, Kejian L. Comparative study on sample size calculation methods. Statistics and Decision 2013; 12: 4-8.
19. Yu M, Xiaohong L, Weizhi L. Preliminary revision of the Chinese version of the Multidimensional Fatigue Inventory in the military grassroots medical staff. Chinese Mental Health J 2008; 16: 658-60.

20. Soriano-Maldonado A, Carrera-RuizA, Diez-FernandezDM, et al. Effects of a 12-week resistance and aerobic exercise program on muscular strength and quality of life in breast cancer survivors: study protocol for the EFICAN randomized controlled trial. Medicine 2019; 98: e17625.

21. Akima H, Kuno S, Suzuki Y, Gunji A, Fukunaga T. Effects of 20 days of bed rest on physiological cross-sectional area of human thigh and leg muscles evaluated by magnetic resonance imaging. J Gravit Physiol 1997; 4: S15-21.

22. Lee SY, Yoon BH, Beom J, Ha YC, Lim JY. Effect of lower-limb progressive resistance exercise after hip fracture surgery: a systematic review and meta-analysis of randomized controlled studies. J Am Med Dir Assoc 2017; 18: 1096 e1019-26.

23. Bade MJ, Struessel T, Dayton M, et al. Early high-intensity versus low-intensity rehabilitation after total knee arthroplasty: a randomized controlled trial. Arthritis Care Res 2017; 69: 1360-8.

24. In G, Taskin HE, Al M, et al. Comparison of 12-week fitness protocols following bariatric surgery: aerobic exercise versus aerobic exercise and progressive resistance. Obes Surg 2021; 31: 1475-84.

25. Chen X, Li X, Zhu Z, Wang H, Yu Z, Bai X. Effects of progressive resistance training for early postoperative fasttrack total hip or knee arthroplasty: a systematic review and meta-analysis. Asian J Surg 2021; 44: 1245-53.

26. Almeida KAM, Rocha AP, Carvas N, Pinto A. Rehabilitation interventions for shoulder dysfunction in patients with head and neck cancer: systematic review and meta-analysis. Phys Ther 2020; 100: 1997-2008.

27. Winther SB, Foss OA, Klaksvik J, Husby VS. Pain and load progression following an early maximal strength training program in total hip- and knee arthroplasty patients. J Orthop Surg 2020; 28: 2309499020916392.

28. Edwards H, Rose EA, King TC. Postoperative deterioration in muscular function. Arch Surg 1982; 117: 899-901.

29. Edwards H, Rose EA, Schorow M, King TC. Postoperative deterioration in psychomotor function. JAMA 1981; 245: 1342-3.

30. Stief F, Kleindienst Fl, Wiemeyer J, Wedel F, Campe S, Krabbe B. Inverse dynamic analysis of the lower extremities during nordic walking, walking, and running. J Appl Biomech 2008; 24: 351-9.

31. Pedersen BK, Saltin B. Exercise as medicine - evidence for prescribing exercise as therapy in 26 different chronic diseases. Scand J Med Sci Sports 2015; 25 Suppl 3: 1-72.

32. Pedersen BK, Saltin B. Evidence for prescribing exercise as therapy in chronic disease. Scand J Med Sci Sports 2006; 16 Suppl 1: 3-63.

33. Petrigna L, Giustino V, Zangla D, et al. Physical fitness assessment in goalball: a scoping review of the literature. Heliyon 2020; 6: e04407.

34. Xu XY, Lu JL, Xu Q, Hua HX, Xu L, Chen L. Risk factors and the utility of three different kinds of prediction models for postoperative fatigue after gastrointestinal tumor surgery. Support Care Cancer 2021; 29: 203-11.

35. Gillani M, Hassan S, Abdullah UH, Saeed Baqai MW, Shamim MS. Quality of life in children treated for craniopharyngiomas. J Pak Med Assoc 2020; 70: 2072-4.

36. Galloway L, Ali M, Lansdown A, et al. The impact of endoscopic transsphenoidal pituitary adenoma surgery on endocrine function: a single-centre study. Acta Neurochir 2021; 163: 391-8. 
37. Pertichetti M, Serioli S, Belotti F, et al. Pituitary adenomas and neuropsychological status: a systematic literature review. Neurosurg Rev 2020; 43: 1065-78.

38. Manojlovic-Gacic E, Bollerslev J, Casar-Borota O. Pathology of pituitary neuroendocrine tumours: present status, modern diagnostic approach, controversies and future perspectives from a neuropathological and clinical standpoint. Neuropathol Appl Neurobiol 2020; 46: 89-110.

39. Schei S, Solheim O, Jakola AS, Sagberg LM. Perioperative fatigue in patients with diffuse glioma. J Neurooncol 2020; 147: 97-107.

40. van der Linden SD, Gehring K, Rutten GM, Kop WJ, Sitskoorn MM. Prevalence and correlates of fatigue in patients with meningioma before and after surgery. Neurooncol Pract 2020; 7: 77-85.

41. Socolovsky M, Bonilla G, Lovaglio AC, Masi GD. Differences in strength fatigue when using different donors in traumatic brachial plexus injuries. Acta Neurochir 2020; 162: 1913-9.

42. Ting W, Yanyao T, Shehua Q. Qualitative study of information needs during diagnosis and treatment of patients with pituitary adenoma resection. Chin J Modern Nursing 2020; 26: 208-12. 